\title{
Representações Sociais da Comunidade sobre o Festival de Inverno de Ouro Preto, Minas Gerais (Brasil) a partir da Evocação Livre de Palavras
}

\section{Community Social Representations about Ouro Preto Winter Festival, Minas Gerais (Brazil) from Free Evocation of Words}

\author{
Aryella Mascarenhas da Silva Reis (REIS, A. M. da S.) $)^{1}$ e \\ Natanael Reis Bomfim (BOMFIM, N. R.) ${ }^{2}$
}

RESUMO - O artigo discorre sobre o Festival de Inverno de Ouro Preto (Minas Gerais, Brasil), a partir das representações sociais construídas pela comunidade sobre esse evento. Para tanto, fez-se uso da Teoria das Representações Sociais e como instrumento de coleta de dados optou-se pela evocação livre de palavras. Assim, identificaram-se os conteúdos dessas palavras o que permitiu compreender os valores, opiniões, mitos, crenças e atitudes da comunidade. A partir disso, foi possível sugerir estratégias para o desenvolvimento do turismo cultural com base na sustentabilidade e a manutenção do festival como instrumento de valorização da cultura local e afirmação da identidade. É importante ressaltar que a pesquisa realizada não apresenta caráter conclusivo, visto que é resultado da percepção de um grupo específico, a partir de dados coletados no ano de 2010, e essas representações são transitórias e sujeitas a novas significações.

Palavras-chave: Representações sociais; Festival de Inverno de Ouro Preto; Cultura; Turismo; Comunidade.

ABSTRACT - This article discusses about Ouro Preto Winter Festival (Minas Gerais, Brazil), from the social representations built by the community about this event. To this study, it was used the Social Representations Theory and as an instrument of data collection it was used the free evocation of words. Thus, it was identified the contents of those words which allowed to understand the values, opinions, myths, beliefs and attitudes of the community. From this, it was possible to suggest strategies for developing cultural tourism based on sustainability and the maintenance of the festival as a mean of valuing the local culture and identity affirmation. It is important to note that the research presented does not have a conclusive character, since it is a result of a specific group perception, from data collected in 2010, and its representations are transient and subject to further meanings.

Key words: Social representations; Ouro Preto Winter Festival; Culture; Tourism; Community.

\footnotetext{
${ }^{1}$ Graduação em Turismo (Bacharelado) pela Universidade Federal do Ouro Preto - UFOP. Especialização em Cultura e Arte Barroca pela UFOP. Mestrado em Cultura e Turismo pela Universidade Estadual Santa Cruz - UESC. Endereço: Rua Sagrada Família, 667 (Bela Vista). CEP: 45997-005. Teixeira de Freitas Bahia (Brasil). Telefone: (73) 8853-0700/ 3011-3080. E-mail: aryellatur@ hotmail.com

${ }^{2}$ Graduação em Geografia pela Universidade Católica de Salvador - UCSAL. Mestrado em Educação pela Universidade Federal da Bahia - UFBA. Doutorado em Educação pela Université du Québec à Montréal (Canadá). Professor adjunto da UESC. Endereço: Universidade Estadual de Santa Cruz, Departamento de Ciências Agrárias e Ambientais. Rodovia Ilhéus - Itabuna, Salobrinho. CEP: 45660000. Ilhéus - Bahia (Brasil). Telefone: (073) 3680-5141. Fax: (073) 3680-2195. E-mail: nabom@hotmail.com
} 


\section{INTRODUÇÃO}

A escolha de um destino turístico depende, dentre outros fatores, das ideias e impressões que compõem o imaginário dos turistas em relação a um determinado lugar. $\mathrm{O}$ imaginário pode ser alimentado, reforçado ou renovado à medida que novas concepções, novos olhares são veiculados e passam a fazer parte do acervo de imagens que representam tal lugar.

Assim, destinos e produtos turísticos são construídos não somente com atrativos, serviços e preço, mas também por um valor agregado, marcado pela necessidade do homem moderno em buscar em suas viagens experiências de qualidade. Em especial, para o turista cultural, essas experiências de qualidade significam estar em harmonia com a comunidade e vivenciar a rotina e a cultura do lugar, ou seja, seu patrimônio.

O patrimônio, nas sociedades contemporâneas, adquire um novo valor revestindo-se de uma nova centralidade, como resultado das construções humanas tornando-se testemunhos de experiências individuais ou coletivas, em um período histórico específico. Desse modo, patrimônio passa a ser entendido como legado cultural recebido do passado e transmitido às novas gerações, com a função intrínseca de materializar as diversas formas de agir, sentir e viver em sociedade (RODRIGUES, 2001; MARTINS, 2006).

Patrimônio, memória e identidade são conceitos relevantes para aqueles que pretendem discutir produto turístico cultural e, consequentemente, os atrativos de um lugar. O município de Ouro Preto (Minas Gerais, Brasil), enquanto produto do turismo cultural pode ser analisado a partir do fato de ser Patrimônio Cultural da Humanidade, título conferido pela Organização das Nações Unidas para a Educação, a Ciência e a Cultura - UNESCO, em 1980 (UNESCO, 2010).

Como cidade patrimônio, Ouro Preto destaca-se no segmento de turismo cultural e apresenta-se como produto turístico, principalmente, pelo valor atribuído ao seu conjunto arquitetônico formado por museus, igrejas e casarões coloniais. Os eventos também compõem o produto do turismo cultural e representam a memória viva da cidade, configurando-se como um agente de um novo ethos social, na medida em que criam novos tipos de relações entre as pessoas, desenvolvem hábitos e costumes e definem novos estilos de ser e viver (MELO NETO, 2001). 
Nesse sentido, o Festival de Inverno de Ouro Preto, apresenta-se como um dos eventos de maior destaque no seu calendário cultural, com grande importância no contexto social, cultural, econômico e político, podendo ser considerado como fato valorizador do seu patrimônio histórico-cultural, já que oferece atividades que promovem o contato entre turistas e moradores, contribuindo para experiências turísticas de qualidade.

A partir do exposto, torna-se necessário desenvolver o chamado turismo cultural, com características de sustentabilidade, que "significa política e estratégia de desenvolvimento econômico e social contínuo [...]" (CORIOLANO, 2006) contando com a participação mais efetiva do poder público, do setor privado e da comunidade, considerando os anseios e expectativas dos grupos sociais envolvidos no processo de organização e realização do Festival com o intuito de evitar a degradação socioambiental e as injustiças sociais.

Diante disso, a pesquisa busca inferir sobre a verdadeira participação da comunidade de Ouro Preto durante a produção e realização do Festival de Inverno de Ouro Preto. De maneira, que seja possível compreender se o festival se configura como evento realizado na cidade, ou se ele pode ser entendido como um acontecimento da cidade alcançando o objetivo de valorização e inserção da comunidade que o acolhe.

Dessa maneira, a pesquisa justifica-se por seu viés científico, na medida em que os possíveis resultados a partir do conteúdo das representações sociais sobre o Festival de Inverno podem ampliar o conceito de patrimônio cultural e sua relação com o planejamento do turismo cultural. E por seu viés social, vez que os conteúdos das representações sociais passam a oferecer pistas que orientem as práticas sociais dos representantes envolvidos no lugar turístico, Ouro Preto.

Essas práticas entendidas como turísticas uma vez reformuladas pela reflexão dos próprios sujeitos podem se configurar como fatores de identidade com a própria cultura local. Como referencial teórico-metodológico recorreu-se à Teoria das Representações Sociais, que se baseia no pressuposto de que os sujeitos inseridos em um universo social comum formulam e compartilham representações que se encontram localizadas em uma grande teia de relacionamentos que os envolvem, definidas como opiniões, crenças, valores, atitudes, mitos, estereótipos sobre o objeto social, neste caso, o Festival de Inverno de Ouro Preto (BOMFIM, 2004). 
Assim, a análise sistemática do conteúdo dessas representações sociais, consideradas como produto das interações entre o sujeito, o outro e o objeto social, se faz indispensável para avaliar as imagens do Festival de Inverno, pois permite explorar as várias formas de conhecimento dos atores da comunidade (MOSCOVICI, 1976; JODELET, 1986). Desse modo, as representações sociais sobre esse evento poderão orientar e esclarecer qual o nível de envolvimento da comunidade com o festival e de que maneira esse pode se apresentar como instrumento de valorização da cultura.

A partir daí, tornar-se-á viável a criação de medidas para atenuar as discrepâncias entre o uso da cidade pela atividade turística e os valores culturais mais suscetíveis às modificações em virtude da presença de visitantes, propondo o uso do espaço baseado na ideia de sustentabilidade.

\section{FESTIVAL DE INVERNO DE OURO PRETO}

A cidade de Ouro Preto localiza-se na Serra do Espinhaço, na Zona Metalúrgica de Minas Gerais, conhecida como Quadrilátero Ferrífero, localizada a 90 quilômetros da capital do estado, Belo Horizonte, com população estimada de 70 mil habitantes a cidade de Ouro Preto reúne um importante acervo da arquitetura e da arte do período colonial brasileiro (IBGE, 2010).

Ouro Preto configura-se como resultado dos diferentes usos da terra, um reflexo da sociedade do passado e do presente que vão deixando marcas na organização espacial, além de materializar crenças, valores e mitos através da construção de monumentos, lugares sagrados, praças, dentre outros (SIVIERO, 2006), esses espaços são considerados lugares de memória porque fazem transcender o valor de uso e adquirem também valor simbólico.

O espaço urbano é formado por elementos materiais e imateriais, resultantes das práticas concretas e dos sistemas simbólicos de cada sociedade, ou seja, das relações entre os atores locais que conferem relação, singularidade e identidade ao espaço geográfico, tornando-o lugar sociável e compartilhado. Assim, o espaço é, ao mesmo tempo, lugar de memórias, subjetividades e, sobretudo, de signos das identidades móveis, dinâmicas. 
Essa constatação pode ser observada, por exemplo, nas configurações das formas festivas que nascem no interior de um grupo social, em especial nos eventos programados e espontâneos. Esses eventos, que reforçam as solidariedades e evidenciam o congraçamento popular exemplificam a relação entre materialidade e imaterialidade que emanam dos espaços urbanos. Além disso, podem ser entendidos como elementos que estruturam, expressam e forjam também um sentimento de identificação, de reconhecimento da comunidade em relação a uma história comum e, consequentemente, suscitam identidades.

Esses espaços, aliados a uma infraestrutura básica composta por bancos, hospitais, postos de saúde, rodoviária; equipamentos e serviços turísticos - agências de receptivo, lojas de artesanatos, cafés, restaurantes, hotéis, pousadas, centro de artes e convenções, cinema e teatros - formam o espaço urbano turístico, que por sua vez é composto de vários lugares turísticos. Então, o lugar turístico é composto por espaços urbanos apropriados pelo turismo, onde há a ocorrência de interações e inter-relações temporárias entre a comunidade e o turista, sendo que esse espaço relacional é permanente para o primeiro e efêmero para o segundo (FRATUCCI, 2009).

Esses elementos formam lugares apropriados para a atividade turística, por meio de adaptações, alocação de infraestrutura, meios de hospedagem, acesso, redefinem objetos, formas, práticas sociais e conteúdos dos espaços urbanos, ressignificando-os para atender às expectativas dos turistas-consumidores, tornando-os lugares turísticos.

Os lugares turísticos são resultado da junção dos elementos preexistentes no lugar associados a uma gama de facilidades e condições que tornam possível a relação de produção e consumo, bem como das relações entre comunidades anfitriãs e visitantes, relações estas que interferem, de forma positiva ou negativa, na dinâmica local, com repercussões na vida social, política, econômica, social e cultural dessas comunidades.

Para Fratucci (2009, p. 131) lugar turístico é o território:

[...] onde o turismo se realiza, e onde há a ocorrência de interações e interrelações temporárias entre o anfitrião e o turista, aos quais irão permitir um contato direto, sem barreiras (físicas ou simbólicas) entre eles e o reconhecimento da existência do outro, recíproca e simultaneamente. 
Assim, para que o turismo aconteça é necessário que haja a apropriação dos lugares e que ocorra interação entre turistas e moradores. Para os turistas essa interação deve resultar em uma experiência positiva baseada nas suas percepções antes da viagem que os levaram a escolher tal destino e, para o habitante, deve ser momento para crescimento pessoal e fortalecimento da noção de pertencimento àquele lugar.

Dessa maneira, o lugar turístico só é passível de existência a partir do momento que se entenda o turismo, de maneira mais abrangente, como:

[...] fenômeno social, produto da experiência humana, cuja prática aproxima e fortalece as relações sociais e o processo de interação entre os indivíduos e seus grupos sociais, sejam de uma mesma cultura, ou de culturas diferentes (GOULART e SANTOS, 1998, p. 19).

Assim, o espaço urbano de Ouro Preto é apropriado pela atividade turística e sofre modificações que vão ao longo do tempo dando novos e diferentes significados a memória e a identidade do lugar. Com isso, se faz necessário pensar o turismo, para além da sua contribuição econômica e manutenção do patrimônio edificado, é importante também considerar o turismo como ferramenta para a valorização da cultura local, consubstanciado em suas festas, em especial, o Festival de Inverno.

Partindo dessa premissa, o Festival de Inverno adquire dupla importância, primeiro por colocar em cena valores, projetos, arte e cultura da comunidade, se tornando, desse modo, um espaço para afirmação da identidade local e segundo por ser importante atrativo do turismo cultural, que baseado nos princípios de sustentabilidade, torna-se capaz de contribuir para mudanças sócio-econômicas positivas para a cidade e sua comunidade.

Esse festival ocorre durante o mês de julho, durante o período considerado de alta temporada para o turismo em Ouro Preto, por coincidir também com o período de férias escolares. Apresenta como característica a promoção da arte e cultura, através de eventos como exposições, shows musicais, palestras e espetáculos teatrais, além de atividades formativas, a partir de oficinas com público-alvo definido.

A primeira edição desse festival ocorreu em julho de 1967, sendo uma iniciativa de um grupo de professores da escola de Belas Artes da UFMG (Universidade Federal de Minas Gerais) que tinha como intuito levar a arte à coletividade, a partir de uma atividade de extensão da universidade (UFOP, 2009a). Nessa edição, os cursos 
oferecidos foram apenas nas áreas de música e artes plásticas. E para realização dessa atividade Ouro Preto foi a cidade escolhida. O festival teve uma segunda edição em 1968 e neste, e nos anos seguintes, aquele se tornou um espaço para debates e reflexões que englobavam questões políticas nacionais e internacionais (UFOP, 2009a; UFMG, 2010).

Notou-se que em alguns anos por falta de verba ou por falta de apoio político o festival não foi realizado na cidade, ou quando realizado teve sua importância reduzida. A desvalorização do festival enquanto espaço de promoção e popularização da arte, se deu, dentre outros motivos, pelo pouco comprometimento do poder público municipal em manter a qualidade das atividades e atrações que compunham tal evento, em especial, na gestão municipal 2001-2004 (CIFELLI, 2005). Com isso, o festival passou a não atingir mais seu objetivo, que consistia em proporcionar à comunidade acesso a arte de qualidade e, consequentemente, passou também a não se destacar no cenário de festivais.

Entretanto, o festival já era uma realidade e um elemento marcante na comunidade eclodindo em três iniciativas diferenciadas: Festival de Inverno da Prefeitura de Ouro Preto, Festival de Inverno do Centro Universitário Belo Horizonte Uni-BH e, em 2004, a UFOP, percebendo a deficiência que atingia esse evento tradicional da cidade, lançou o Fórum das Artes, evento paralelo ao festival que tinha como objetivo consolidar a região como espaço propício ao estudo das artes e à exploração e desenvolvimento de novas tendências e linguagens artísticas que contribuíssem para a discussão sobre o patrimônio cultural nas cidades (UFOP, 2009b).

O Fórum dividia-se, basicamente, em duas modalidades: atividades formativas (as oficinas e cursos) e os eventos (apresentações de artes cênicas, música, exposições, lançamentos de livros e CDs). No ano de 2005, pela primeira vez, o festival foi realizado pela UFOP em parceria com as Prefeituras Municipais de Ouro Preto e Mariana. Nessa primeira edição, o festival recebeu o nome de "Festival de Inverno de Ouro Preto - Fórum das Artes 2005" e teve como tema "Estrada Real" (UFOP, 2009a).

Em sua nova formatação sob a direção da UFOP, a cada ano é escolhido um tema e um personagem - arquétipo que se destacou na história e no imaginário popular das cidades envolvidas, ou seja, Ouro Preto e Mariana - que são trabalhados durante o festival. Desta maneira, o evento busca contribuir para o desenvolvimento local por 
meio da democratização da cultura e da possibilidade de engajamento da comunidade anfitriã em relação à valorização e divulgação da cultura local, de maneira que também incremente o desenvolvimento da atividade turística na cidade.

Por seu caráter cultural, o evento conta com o apoio de entidades públicas e privadas e envolve vários tipos de manifestações artísticas e culturais. Além disso, o festival ocorre durante um período que dura em média vinte dias, sendo que as atividades são distribuídas durante todo o dia. Com isso, é possível hipotetizar que o festival deveria ter uma grande participação da comunidade, além de turistas que chegam à cidade para participar do evento ou, então, os que aproveitam sua estada em Ouro Preto para vivenciar as oportunidades que tal evento proporciona.

Ao analisar o histórico do festival, é possível inferir que em alguns períodos o evento foi realizado e idealizado para atender aos interesses e expectativas que não representavam os interesses da comunidade. A partir dessa constatação, pretende-se entender se o festival configura-se como instrumento de valorização da cultura e da comunidade e se essa enxerga o Festival como um evento próprio da cidade, que representa a sua arte e a sua cultura, para além do seu uso turístico.

\section{REPRESENTAÇÕES SOCIAIS COMO TEORIA E MÉTODO APLICADO AO TURISMO CULTURAL}

Não há nada mais vasto do que as habilidades do ser humano, dentre elas a sua capacidade de representar, em que o sujeito como produtor de significados confere sentido às suas ações e experiências como meio de se relacionar com o mundo. Nesse contexto, emerge o conceito de representação social entendida como o conjunto de ideias, imagens, concepções e visões de mundo que os atores sociais constroem sobre a realidade, elaborado de acordo com seus interesses específicos e a partir da própria dinâmica da vida cotidiana.

Assim, abordar as representações sociais no turismo é estabelecer sua relação entre as imagens mentais produzidas pelos atores sociais de Ouro Preto a respeito do Festival de Inverno como atrativo turístico e fenômeno cultural, visto que o homem tem a tendência natural de fragmentar a realidade e classificar as coisas de acordo com os 
interesses vigentes. Assim sendo, as classificações feitas pela comunidade poderão facilitar o desenvolvimento do turismo cultural de forma sustentável, visto que ao planejá-lo serão considerados os interesses implícitos nas representações sociais dos grupos que compõem a sociedade.

O conceito das representações sociais surge a partir da proposta do sociólogo Émile Durkheim (2003) sobre representações coletivas. No entanto, apesar de suas origens na sociologia, a teoria das representações sociais identifica-se com as proposições da psicologia social, em que considera o homem a partir dos processos de interações, como a linguagem, em que os indivíduos mantêm contato com o seu grupo e outros grupos sociais, por isso devem ser considerados em sua essência, ou seja, enquanto ser social. Isso pode ser corroborado na medida em que se objetiva apreender o conteúdo das representações sociais constituídas acerca do Festival de Inverno como na linguagem que se manifesta culturalmente através dos hábitos, costumes, crenças, modo de vida de um povo.

A comunicação e a linguagem são constitutivas e constituintes do sujeito e das suas representações, a mediação pelos signos possibilita e sustenta a relação social, pois é o processo de representação que permite a comunicação entre as pessoas (MOREIRA; OLIVEIRA, 2000, p. xi). Logo, é possível pensar o Festival de Inverno como um elemento dessa comunicação, já que esse evento coloca a população local em contato com turistas e visitantes que chegam a Ouro Preto também com suas vivências, modo de ver o mundo e interpretá-lo.

Em sua teoria, Moscovici (1976) considera o indivíduo como um sujeito ativo e construtor, assim, para ele não há como considerar o sujeito e o objeto de forma dicotômica. Desse modo, os indivíduos não se comportam passivamente diante do mundo e os conteúdos que a sociedade oferece são pensados e reformulados na medida em que eles se constituem como seres ativos.

Diante dessa proposição, a visão de mundo dos ouropretanos acerca do Festival de Inverno reveste-se de significados que contribuem para reflexão e elaboração de estratégias voltadas para o desenvolvimento sustentável do turismo, que no seu contexto cultural pressupõe a pluralidade e a diversidade cultural, o respeito dos valores e às tradições locais, a preservação e valorização do patrimônio cultural, das identidades, o 
desenvolvimento da capacidade de autogestão, possibilitando o aproveitamento racional e equilibrado dos recursos culturais (SACHS, 2004; BARRETTO, 2007).

Desse modo, a análise e interpretação das representações sociais sobre o Festival de Inverno aliadas ao conceito de sustentabilidade cultural possibilita fomentar ações que contribuam para o uso de eventos culturais como meio de valorização da cultura e o sentimento de pertencimento da comunidade local, no lugar turístico que faz parte do seu cotidiano.

Para Arruda (2002) a Teoria da Representação Social operacionaliza um conceito para se trabalhar com o pensamento social em sua dinâmica e em sua diversidade. Para ele a teoria parte da premissa de que existem diferentes formas de se comunicar e se conhecer, guiadas por objetivos diferentes.

Nessa teoria, as formas de representação e de expressão das sociedades são formadas a partir do senso comum e estas, por sua vez, são geradas pelos fenômenos sociais, como as conversações e outras circunstâncias como as ciências, as religiões e as ideologias. As representações sociais:

[...] entram para o mundo comum e cotidiano em que nós habitamos e discutimos com nossos amigos e colegas e circulam na mídia que lemos e olhamos. Em síntese, as representações sustentadas pelas influências sociais da comunicação constituem as realidades de nossas vidas cotidianas e servem como principal meio para estabelecer as associações com as quais nós nos ligamos uns aos outros. (DUVENN, 2009, p. 8).

Nesse sentido, vale respeitar as experiências vividas pelos sujeitos no espaço urbano de Ouro Preto uma vez que elas são parte integrante do cotidiano e, possivelmente, estão associadas ao Festival de Inverno entendido como prática social, momento em que sendo parte integrante do espaço, constroem tanto relações de poder como relações sociais. Haja vista que para a realização do Festival existe todo um processo de criação e produção que envolve vários grupos da sociedade desde a sua concepção, passando pela realização e terminando com os retornos econômicos e culturais proporcionados pelo evento.

É necessário considerar ainda que para Moscovici (2009), as representações sociais são muito além de guias comportamentais. Elas configuram o ambiente para torná-lo propício ao desenrolar das atitudes e emprestam sentido ao comportamento, integrando-o a uma rede de relações. Observa-se, então, uma estreita relação entre as 
representações sociais e o contexto de vida dos sujeitos. Pode-se verificar que as representações sociais revelam as práticas sociais dos atores sociais nos ambientes. Logo, elas podem servir para orientar práticas do turismo cultural.

Em relação à estrutura das representações sociais, Moscovici (2009), afirma que existem dois processos que atuam na formação das representações sociais, a objetivação e a ancoragem, e seus desdobramentos, a saber, o núcleo central e o sistema periférico.

A objetivação é tida como o processo pelo qual os conceitos adquirem materialidade, assim o objeto desconhecido após a objetivação, transforma-se em algo efetivamente objetivo, concreto, principalmente natural. Já a ancoragem pode ser entendida como um processo ligado à conferência de sentido aos objetos que se apresentam à compreensão humana, ancorar é transpor ideias estranhas para um contexto familiar, reduzi-las a categorias e imagens comuns (MACEDO, 2006).

[...] Esses mecanismos transformam o não-familiar em familiar, primeiramente transferindo-o a nossa própria esfera particular, onde nós somos capazes de compará-lo e interpretá-lo e depois reproduzindo-o entre as coisas que nós podemos ver e tocar, e, consequentemente, controlar. (MOSCOVICI, 2009, p. 60-61).

Isso significa ler e interpretar a realidade empírica acerca do Festival de Inverno de Ouro Preto, por meio das representações sociais construídas e, dessa maneira, é possível inferir quais elementos são familiares aos grupos sociais e, podem ser resultado, dentre outros fatores, da influência do desenvolvimento da atividade turística na cidade.

Assim, a familiaridade revela-se como elemento importante para essa teoria, desta maneira, se há a familiaridade existe então a representação presente. Para Abric (2000), em sua teoria que complementa o trabalho de Moscovici, as representações sociais são constituídas de um sistema sócio-cognitivo formado pelo núcleo central e seus elementos periféricos.

O núcleo central é resultante da natureza do objeto representado, a partir das relações entre o grupo e o objeto, além do sistema de valores e normas sociais que constituem o meio ambiente ideológico atual e do grupo. Já os elementos periféricos organizam-se em torno do núcleo central e são mais acessíveis, mais concretos e mais vivos. 
Entende-se aqui que se pode, por meio da evocação livre de palavras em torno do Festival de Inverno, apreender o núcleo central e seus elementos periféricos como forma de entender as representações construídas, tendo em vista que Ouro Preto enquanto espaço turístico urbano proporciona aos indivíduos interagir com diferentes classes e culturas, que possuem diferentes tipos e modos de ver e compreender o mundo.

Assim, percebe-se que esse sistema permite compreender uma das características fundamentais das representações: elas são estáveis e rígidas no que se refere ao núcleo central onde encontram ancoradas, no sistema de valores partilhados pelos membros de um grupo e, por isso, mais resistentes a mudanças.

E do mesmo modo, as representações são móveis e flexíveis, visto que associadas às características individuais estão dispostas a modificarem-se no intuito de englobar eventos, ideias, objetos, que sejam contraditórios a priori, para, ao interagir com esta novidade, integrá-la na representação pré-existente ou criar uma nova representação.

Então, pode-se considerar que as representações sociais têm um papel importante como mediadoras entre as esferas do individual e do objeto social. Elas são um conjunto de conceitos e afirmações que têm sua origem nas interações sociais. Sendo a expressão, representações sociais, utilizada para designar um conjunto de fenômenos que permite definir o conceito, como um conjunto teórico construído em torno da própria noção de representação social (SOUZA, 2008).

Sendo assim, as representações sociais respondem a quatro funções essenciais (ABRIC, 2000). A primeira delas é a função de saber por permitir compreender e explicar a realidade, é o saber prático do senso comum, a manifestação do esforço permanente do homem para compreender e comunicar. A segunda função é identitária, visto que elas definem a identidade e permitem a proteção de especificidade dos grupos, ou seja, das características do sistema central. A terceira função essencial das representações diz à função da orientação, pois elas guiam os comportamentos e práticas. E, por fim, a função justificadora por permitir a argumentação que justifique as tomadas de posição e dos comportamentos.

Nesse sentido, apreender as representações sociais construídas acerca do Festival de Inverno consiste em buscar entender o significado que os atores dessa comunidade 
atribuem a ele. Ao mesmo tempo é verificar como seu conteúdo está revestido de simbologia e ideologia, a partir das circunstâncias do cotidiano local. É uma maneira de entender até que ponto a comunidade é influenciada pelo turismo e qual o grau de envolvimento e afinidade com a atividade.

Portanto, as representações sociais acerca do Festival permitem a interpretação de ações e comportamentos dos grupos sociais visando à compreensão de seus significados, assim sendo poderá se constituir como ferramenta importante no planejamento integrado e sustentável do turismo cultural, em que se considerem as necessidades e anseios dos setores públicos, privados e da comunidade.

\subsection{DESENHO METODOLÓGICO DA PESQUISA}

Este estudo visou identificar e analisar as representações sociais construídas pela comunidade ouropretana sobre o Festival de Inverno a fim de identificar opiniões, crenças, mitos, valores, atitudes, estereótipos e preconceitos como substrato capaz de evidenciar as práticas culturais exercidas nesse lugar turístico.

Assim, a análise sistemática do conteúdo dessas representações, considerada como um produto das interações entre o sujeito, o outro e o objeto social, fez-se indispensável para avaliar as imagens dessa manifestação cultural, pois estas podem permitir explorar as várias formas de conhecimento dos atores da comunidade (MOSCOVICI,1976; JODELET,1986).

O trabalho adotou uma abordagem qualitativa/interpretativa tendo como caminho metodológico a representação social, visto que o interesse de pesquisa estava voltado para o conteúdo das representações sociais como modo de entender o fenômeno enquanto processo.

Assim, por um lado o estudo caracteriza-se como qualitativo na medida em que agrega elementos de significância e intencionalidade aos atos praticados pelos atores sociais nos seus espaços de vida, logo buscou-se apreender a totalidade coletada visando, em última instância, atingir o conhecimento de um fenômeno que é significativo em sua singularidade (MINAYO, 1992).

E é, por outro lado, interpretativa, já que apreendeu-se através da objetivação do fenômeno o significado que os atores sociais atribuem a ele, tornando possível a partir 
do suporte teórico apresentado, reconstruir a realidade empírica sem distorcê-la (BOMFIM, 2004).

A cidade de Ouro Preto foi escolhida como local de estudo por apresentar algumas características próprias, dentre elas o título de Patrimônio Cultural da Humanidade (UNESCO, 2010). Com isso, Ouro Preto é vista como um importante destino do turismo cultural e o Festival de Inverno como importante instrumento de promoção da arte e cultura local. Nesse sentido, o evento "Festival de Inverno de Ouro Preto e Mariana - Fórum das Artes" permitiu um estudo que contemplou as temáticas, cultura e turismo, nas suas particularidades e especificidades.

Em se tratando de uma pesquisa social, além do recorte espacial, o local escolhido justifica-se por ser ocupado por pessoas e grupos que convivem numa dinâmica de interação social influenciada pela atividade turística que pode trazer mudanças e transformações, sejam elas positivas ou negativas, na cultura e identidade local (NETO, 1994). Assim, os locais para coleta dos dados, foram considerados a partir das referências onde o evento acontece.

Para a realização da pesquisa foram considerados os moradores com mais de 20 anos de residência em Ouro Preto, por manterem alguma relação de afetividade com o local e por terem vivenciado várias fases do festival de inverno, objeto desta pesquisa. Para tanto, foi utilizada uma amostra do tipo não-probabilística intencional por exaustão, aplicada aos moradores em localidades consideradas como vetor de fluxo de pessoas para soluções e serviços diversos, entre eles: casas bancárias e casas lotéricas, para os moradores do Centro, e posto de saúde e supermercados, para os moradores do bairro Antônio Dias e Pilar. A coleta de dados em cada bairro aconteceu em horário comercial, no período de três dias, no mês de novembro de 2010.

Como instrumento de coleta de dados optou-se pela técnica da associação de ideias ou evocações livres de palavras. A associação ou evocação livre consiste como técnica para coletar os elementos constitutivos do conteúdo de uma representação. Com o uso dessa técnica tornou-se possível identificar a frequência e a ordem média de associação de palavras o que garante uma aproximação dos elementos de uma representação. A técnica propicia a atualização de elementos implícitos ou latentes que seriam perdidos ou mascarados nas produções discursivas (ABRIC, 1994). Desse modo, 
a técnica de evocações livres mostra-se útil para o entendimento de percepções, atitudes e estereótipos que compõem e estruturam as representações sociais.

Por isso, ao considerar os objetivos da pesquisa e as categorias temáticas do problema de pesquisa, utilizou-se como palavras indutoras: FESTIVAL, INVERNO e OURO PRETO. Essas palavras evocadas serviram de base para que os participantes da comunidade entrevistados descrevessem suas opiniões, ideias e valores sobre o objeto da pesquisa. Assim, foram feitas as seguintes perguntas:

- O que o FESTIVAL representa para você?

- O que representa o INVERNO para você?

- O que representa OURO PRETO?

Para análise dos resultados, utilizou-se a análise das palavras na associação livre a partir da freqüência com que elas ocorreram, bem como pela semelhança semântica (ABRIC, 2000).

Assim, o conteúdo das representações sociais sobre o Festival de Inverno de Ouro Preto deu-se a partir do maior número de palavras agrupadas semanticamente em quadros, para em uma análise posterior apreender os elementos do conteúdo das representações sociais, definido pela frequiência das evocações dos saberes partilhado pelos grupos sociais.

\section{A IMAGEM DO FESTIVAL A PARTIR DA EVOCAÇÃO LIVRE DE PALAVRAS}

O mapa conceitual sobre o Festival de Inverno de Ouro Preto, conforme Figura 1, é resultado da superposição de mapas conceituais específicos das palavras evocadas durante o recolhimento de dados, sendo elas: FESTIVAL, INVERNO e OURO PRETO.

Os mapas específicos de cada palavra evocada foram analisados e interpretados separadamente, tornando possível a criação de um mapa conceitual que agregasse as três palavras em um só mapa e trouxesse as representações sociais sobre o objeto de estudo, nesse caso, o Festival de Inverno de Ouro Preto.

Para tanto, foram aplicados 240 questionários, com três questões que resultaram em 1200 palavras cada. Para o mapa conceitual final sobre o evento foi considerado o 
conjunto de 3600 palavras. Essas palavras sinônimas e semanticamente próximas nas diversas categorias foram agrupadas em ordem decrescente de frequência, a quantidade de palavras agrupadas aparece entre parênteses na Figura 1, de acordo com a categoria em que foi classificada.

Nessa etapa do estudo, foi solicitado aos moradores com mais de 20 anos de residência em Ouro Preto que escrevessem cinco palavras que viessem a sua mente quando pensassem em FESTIVAL, INVERNO e OURO PRETO. Esses dados nortearam a criação do mapa conceitual sobre o Festival de Inverno de Ouro Preto e representam as opiniões, ideias, crenças, atitudes, valores, preconceitos, estereótipos e mitos sobre o objeto social.

Ao analisar os dados presentes na Figura 1 foi possível perceber que a imagem com maior destaque está ligada a ideia de cultura e se desdobra em mais dois elementos, são eles: as manifestações culturais e o sentimento de pertença.

A cidade foi considerada pelos sujeitos entrevistados como espaço de cultura, de feitos históricos, cidade patrimônio, das artes e da diversidade. Ideias estas construídas ao longo do tempo e influenciadas pelas construções políticas impostas em momentos específicos como a ditadura.

Essa imagem também é reforçada pelo convívio diário das pessoas com monumentos e igrejas do período colonial, que continuam preservados e, em sua maioria, com novos usos. O festival também contribui com a valorização e reforço dessa imagem construída de Ouro Preto por sua comunidade, visto que busca colocar em cena as características da cultura local.

Enquanto espaço de construção do conhecimento, destaca-se a presença marcante de instituições federais de ensino em nível técnico e superior capazes de atrair estudantes de todo o país. Por agregar características ligadas à cultura e também a educação, Ouro Preto destaca-se como lugar turístico e também como pólo educacional o que também contribui para grande movimentação de pessoas na cidade. Essa movimentação acentua-se durante a realização do festival, visto que consegue reunir no mesmo local: moradores, turistas e estudantes interessados em vivenciar e aprender sobre arte e cultura em geral. 


\section{REPRESENTAÇÕES SOCIAIS DO FESTIVAL DE INVERNO DE OURO PRETO A PARTIR DA EVOCAÇÃO LIVRE DE PALAVRAS}

\section{Conceito de Cultura}

Cultura - Diversidade Incentivo - Criatividade História - Patrimônio - Arte (634)

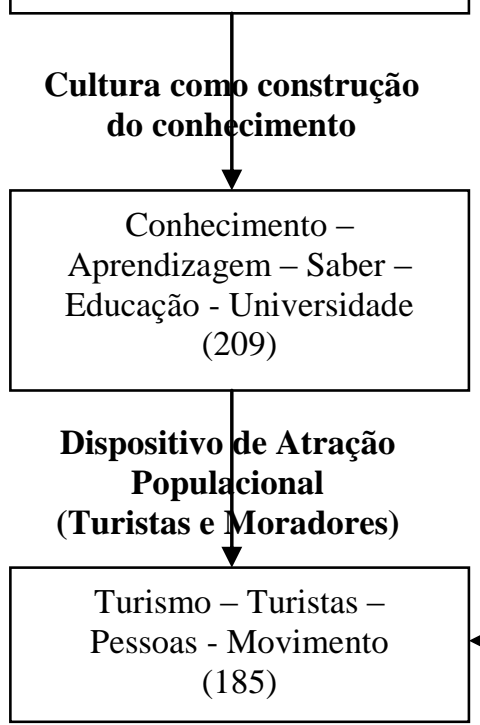

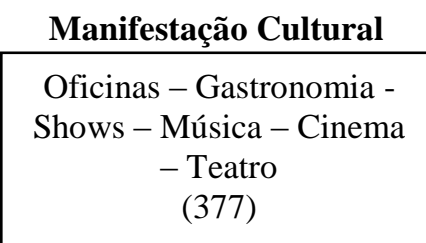

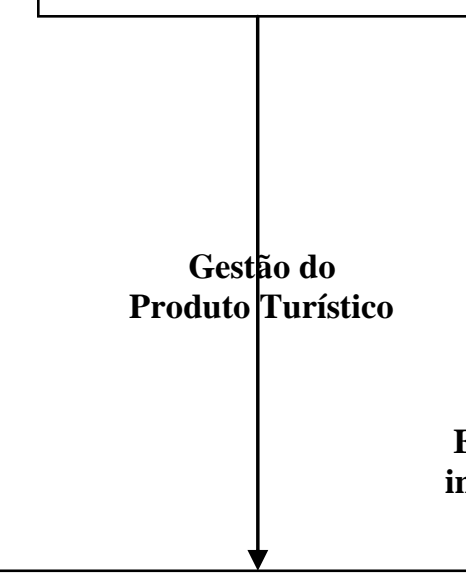

Renda - Trabalho - Economia Desenvolvimento - Oportunidade (244)

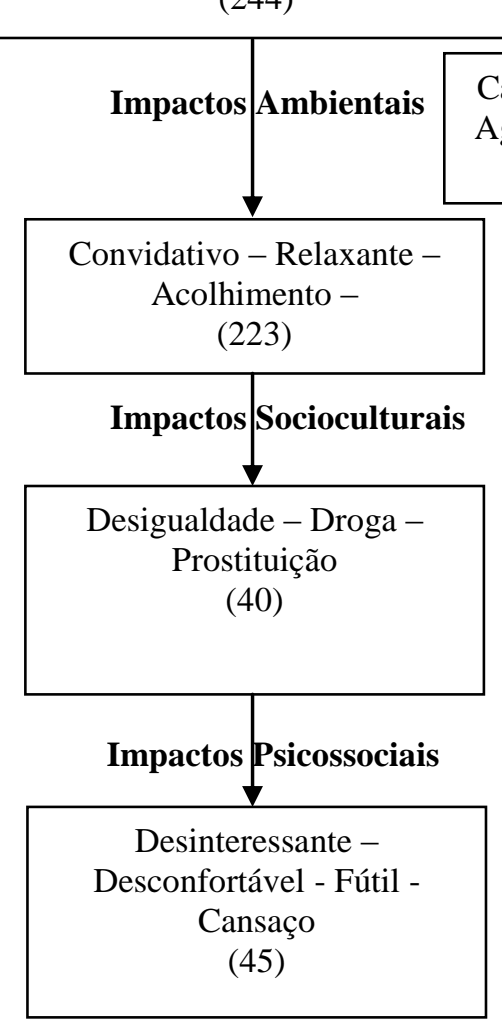

Sentimento de Pertença

Alegria - Bom Importante - Beleza Tudo (433)

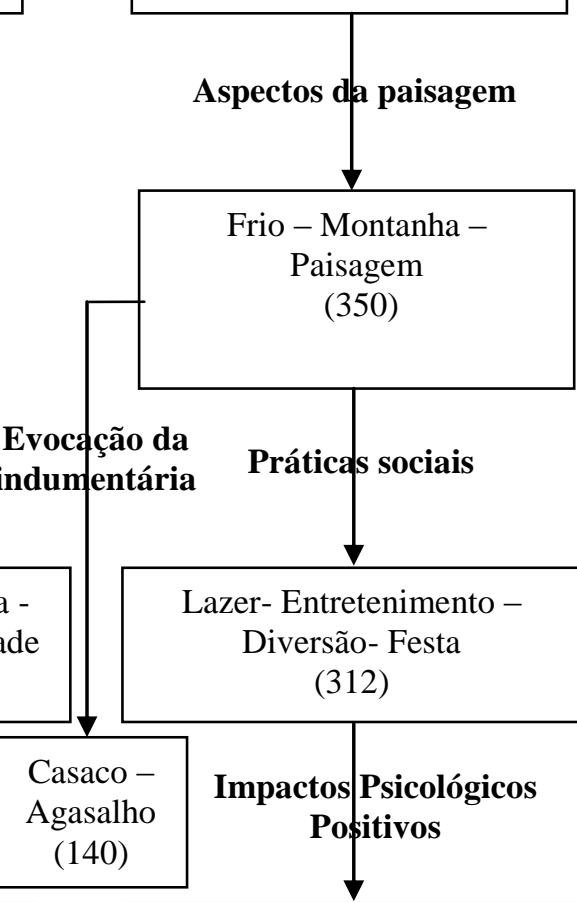

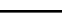
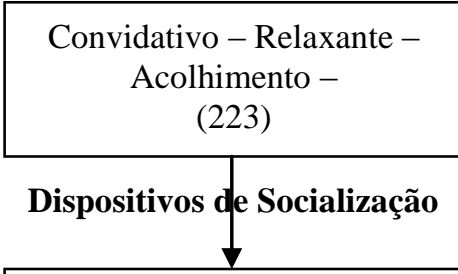

Experiência -

Relacionamento - Interação - Amizade (191)

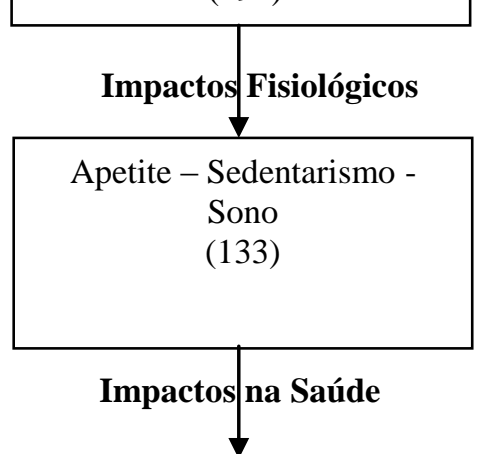

FIGURA 1 - MAPA CONCEITUAL DO FESTIVAL DE INVERNO DE OURO PRETO A PARTIR DA EVOCAÇÃO LIVRE DE PALAVRAS.

FONTE: DADOS DA PESQUISA (2011). 
Ao representar o festival como manifestação cultural destaca-se a importância dada ao papel das oficinas, como elemento formativo em diversas áreas como música, cinema e teatro. Além das oficinas o evento oferece atividades diversas como exposições, shows e espetáculos teatrais, o que modifica o lugar turístico e contribui para o congraçamento de pessoas. Assim, o Festival torna-se capaz de congregar grupos sociais distintos e com interesses diversos, sendo capaz de contribuir com a geração de emprego e renda.

No entanto, há de se considerar que como toda atividade econômica o turismo e o Festival são capazes de gerar impactos de cunho ambiental, como a desorganização, bagunça e sujeira, impactos socioculturais como a desigualdade social, consumo de drogas e prostituição e também impactos psicossociais no momento em que os sujeitos entrevistados consideram o evento como desinteressante e fútil.

É importante atentar-se que os impactos negativos referentes ao festival no universo de 3600 palavras ocorreram 129 vezes, o que correspondeu a somente 3\% (três por cento) das palavras citadas. Outro dado relevante relativo às representações sociais sobre o Festival a partir da evocação livre de palavras é o seu importante papel como fortalecedor do sentimento de pertença da comunidade. Palavras como "alegria", "bom" e "tudo" apareceram como imagem da cidade de Ouro Preto e também do Festival.

Sendo assim, demonstra que apesar de sua formação arquitetônica colonial, os sentimentos e valores atribuídos à cidade e aos seus acontecimentos são contemporâneos, o que garante a sustentabilidade do atrativo, visto que a construção cultural de outros tempos tem incorporado a si novos significados.

Esses fatos demonstram que se em outros tempos Ouro Preto serviu apenas como discurso ideológico, em que sua comunidade não se sentia incluída na sua história, hoje passa por transformações e novas representações são formadas sobre a cidade, o patrimônio e os eventos que nela ocorrem.

Percebeu-se também que aspectos ligados a paisagem também fazem parte do imaginário dos sujeitos, dentre eles, destacam-se o frio, a neblina e as montanhas que compõem o cenário de Ouro Preto durante a realização do Festival de Inverno e remetem a tempo de lazer, entretenimento e festa. Merece destaque os impactos psicológicos positivos como clima convidativo e relaxante, além da beleza local marcada pela natureza, presença de morros e ladeiras e da arquitetura peculiar. 
Para muitos sujeitos, Ouro Preto representa o seu lar, espaço de encontro e formação da família. E o festival torna-se momento de reunir familiares e criar novas relações de amizade, profissionais e amorosas. O clima de férias e o próprio frio típico do período em que acontece o festival, fez com que elementos ligados à indumentária como casacos e agasalhos fossem citados pelos entrevistados.

Foram citados ainda elementos ligados a características fisiológicas como apetite, sedentarismo e sono. E também elementos ligados à saúde como gripe e alergia provocadas pelo frio e grande umidade durante o inverno. Percebeu-se assim, que as representações sociais construídas pelos sujeitos entrevistados, moradores da cidade há pelo menos 20 anos, já considera a importância do turismo como atividade econômica e também de sua influencia para a valorização da cultura local.

É relevante registrar ainda que ao longo do tempo as representações se modificam, assim a cidade antes considerada como obra de arte e, por isso, com características que a tornam intocável, transforma-se em lugar de vivência e trocas de experiências.

\section{CONSIDERAÇÕES FINAIS}

As representações sociais da comunidade de Ouro Preto consideradas nesse estudo são resultado da avaliação e junção dos resultados obtidos a partir da análise da imagem do evento capturada através de Evocação Livre de Palavras, aplicada aos moradores com mais de 20 anos de residência em Ouro Preto.

Como sugerido por Araujo (2008) o estudo das representações sociais reflete a maneira como os indivíduos se percebem em relação à sociedade mais ampla, como se sentem diante da realidade, deixando emergir os sentimentos, ações e informações que reuniram, transformando-as em senso comum, como forma de explicar a sua realidade. Por esse motivo, consideram-se as representações sociais como a imagem da realidade de cada um, registradas também na memória coletiva de cada grupo social.

Para o grupo entrevistado a imagem construída sobre o Festival é resultante de dois processos importantes para a familiarização do grupo com o desconhecido: a objetivação e a ancoragem. A objetivação permite aos sujeitos incorporar novos dados 
aos antigos, de maneira que o permita explicar as relações dos indivíduos. Já a ancoragem permite a ligação das representações sociais já existentes ao que é novo, julgando de acordo com o conjunto de fatos que o grupo já conhece.

Assim, pode-se inferir que o Festival de Inverno, como instrumento cultural, é capaz de valorizar os aspectos culturais do local, criando oportunidade para os residentes de participar de eventos artísticos, oficinas de capacitação que não seria possível de outra maneira, além de proporcionar a troca de experiência entre artistas e pessoas interessadas em temas que compõem o Festival. Percebeu-se então que as atividades propostas pelo evento proporcionam conhecimento e interesse pelas artes, capazes de influenciar no modo de viver e de ver o mundo da comunidade.

Ao longo dos anos, o conjunto de intervenções artísticas, debates e a troca de experiências entre comunidade, realizadores e turistas permitiu que a comunidade passasse a considerar e refletir opiniões antes consideradas contrárias as suas. Desse modo, a partir dos processos de familiarização aos quais as representações sociais são submetidas, essas se adequam e se moldam a nova realidade da cidade que é influenciada pela atividade turística.

Mesmo que alguns dos sujeitos entrevistados tenham considerado o Festival como um evento para turistas, o que se tem como parte das representações sociais do Festival de Inverno de Ouro Preto é a sua função enquanto instrumento de valorização da identidade e, consequentemente, do sentimento de pertencimento.

A análise dos relatos coletados permitiu identificar, a partir da recorrência de prioridades de significados, que a representação social do Festival que mais se destacou foi seu uso como instrumento de divulgação e valorização da cultura e das artes.

Assim sendo, é possível afirmar que a pesquisa alcançou os objetivos propostos já que se verificou haver uma participação efetiva da comunidade durante o evento que passou a ser considerado pelos seus moradores como um evento que traz contribuições também para suas vidas e não somente para os turistas que visitam Ouro Preto.

No entanto, para garantir a continuação e qualidade é importante que o Festival seja institucionalizado pela Universidade Federal de Ouro Preto, passando a compor o calendário oficial e permanente da instituição. Essa medida poderá garantir patrocínios e parceiros ao longo dos anos, e poderá garantir a estabilidade financeira e qualidade cultural do evento. 
É importante ressaltar que mesmo sendo uma ação da Universidade o evento precisa estar em sintonia com a comunidade que o recebe, os residentes devem se sentir como parte, extensão do acontecimento e não dissociados do lugar. Essa atitude pode potencializar a interação de práticas sociais e culturais da cidade.

Nesse contexto, o Festival de Inverno pode se firmar como instrumento de valorização e afirmação de uma cultura que caracterize a identidade ouropretana, que leve os moradores a valorizar e ressignificar seu passado. Para tanto, é importante que haja uma verdadeira inserção da comunidade em todo o processo de produção e execução do evento. Oficinas, espetáculos e exposições devem continuar a valorizar a arte, as histórias e a cultura local, de maneira que a comunidade se aproprie cada vez mais do evento, como uma de suas tradições.

\section{REFERÊNCIAS}

ABRIC, J. C. Pratiques sociales et représentations. Paris: PUF, 1994.

A abordagem estrutural das representações sociais. In: MOREIRA, A. S. P.; OLIVEIRA, D. C. O. (Orgs.). Estudos interdisciplinares de representação social. 2. ed. Goiânia: AB, 2000. p. 27-38.

ARAUJO, M. C. A teoria das representações sociais e a pesquisa antropológica. Revista Hospitalidade, São Paulo, ano V, n. 2, p. 98-119, jul.-dez. 2008.

ARRUDA, A. Teoria das Representações Sociais e Teorias de Gênero. Cadernos de Pesquisa, n. 117, p. 127-147, nov. de 2002.

BARRETTO, M. Cultura e Turismo: Discussões Contemporâneas. Campinas, SP: Papirus, 2007 (Coleção Turismo)

BOMFIM, N. R. Représentation sociale de l'e space et enseignement/aprentissage de la géographie scolaire chez les élèves "favelados" d'une ville au nord-est du Brésil. 193 f. Tese (Doutorado em Educação) - Faculdade de Educação, Universidade do Quebec, Montreal, Canadá, 2004.

CIFELLI, G. Turismo, patrimônio e novas territorialidades em Ouro Preto, MG. 245 f. Dissertação (Mestrado em Geografia) - Instituto de Geociências, Universidade Estadual de Campinas, Campinas, 2005. 
CORIOLANO, L. N. M. T. Turismo e meio ambiente: a (in) sustentabilidade em questão. Revista de Estudos Turísticos, 20, ago 2006. Disponível em:

$<$ http://www.etur.com.br/conteudocompleto.asp?IDConteudo=11163>. Acesso em: 20/09/2010.

DURKHEIN, E. As Formas Elementares da Vida Religiosa. São Paulo: Martins Fontes, 2003.

DUVEEN, G. O poder das ideias. Introdução. In: MOSCOVICI, S. Representações Sociais: investigações em Psicologia Social. Petrópolis, RJ: Vozes, 2009. p. 7-28.

FRATUCCI, A. C. Os Lugares Turísticos: Territórios do Fenômeno Turístico. GEOgraphia, América do Norte, 2, set. 2009. Disponível em: <http://www.uff.br/geographia/ojs/index.php/geographia/article/view/45/43>. Acesso em: 22/09/2010.

GOULART, M.; SANTOS, R. I. C. dos. Uma abordagem histórico-cultural do turismo. Turismo - Visão e Ação, v. 1, n. 1, p. 19-28, jan./jun. 1998.

IBGE. População da Cidade de Ouro Preto, Minas Gerais. Disponível em: <www.ibge.gov.br>. Acesso: 18.12.2010.

JODELET, D. La representación social: fenómenos, concepto y teoría. In: MOSCOVICI, S. (Org.). Psicologia Social II. Barcelona/México: Paídos, 1986. p. 469494.

MACEDO, F. M. F. Estudo das representações sociais de docentes do curso de Turismo da UNOPAR sobre avaliação. 103 f. Monografia (Especialização em Metodologia do Ensino Superior), Universidade Norte do Paraná, Londrina, 2006.

MARTINS, C. Patrimônio Cultural e identidade: significado e sentido do lugar turístico. In: Roca, 2006.

(Org.). Patrimônio Cultural: da memória ao sentido de lugar. São Paulo:

MELO NETO, F. P. Evento: de ação, de entretenimento a agente de promoção do patrimônio histórico-cultural. In: FUNARI, P. P; PINSKY, J. (Orgs.). Turismo e patrimônio cultural. São Paulo: Contexto, 2001. (Coleção turismo Contexto) p. 53-66

MINAYO, M. C. S. O desafio do conhecimento: pesquisa qualitativa em saúde. São Paulo - Rio de Janeiro: Hucitec- Abrasco, 1992.

MOREIRA, A.; OLIVEIRA, D. C. (Orgs.). Introdução. Estudos interdisciplinares de representação social. 2. ed. Goiania: $A B, 2000$. p. xi-xii.

MOSCOVICI, S. La psychanalyse, son image et son public. Paris: P. U. F, 1976. Vozes, 2009.

Representações Sociais: investigações em Psicologia Social. Petrópolis, RJ: 
NETO, O. C. O trabalho de campo como descoberta e criação. In: MINAYO, M. C. (Org.). Pesquisa social: teoria, método e criatividade. Petropólis: Vozes, 1994.

RODRIGUES, M. Preservar e consumir: o patrimônio histórico e o turismo. In: FUNARI, P. P.; PINSKY, P. P (Orgs.). Turismo e patrimônio cultural. São Paulo: Contexto, 2001. (Coleção Turismo Contexto) p. 15-24.

SACHS, I. Desenvolvimento: includente, sustentável, sustentado. Rio de Janeiro: Garamond, 2004.

SIVIERO, A. P. Os elementos do espaço turístico urbano no processo de planejamento: reflexões teóricas e articulações. Revista RAEGA, Curitiba, n. 11, p. 51-59, 2006. Editora UFPR.

SOUZA, M. L. M. As representações sociais da comunidade sobre elementos culturais e turísticos da Vesperata em Diamantina, Minas Gerais. 118 f Dissertação (Mestrado em Cultura e Turismo), Universidade Estadual de Santa Cruz, Ilhéus, 2008.

UFMG. VARELLA, J. Festival é referência para a cultura nacional. Disponível em: <http://www.ufmg.br/boletim/bol1239/pag5.html>. Entrevista concedida a Marco Antonio Corteleti. Acesso em: 18/08/2010.

UFOP. Festival de Inverno de Ouro Preto e Mariana - Fórum das Artes. O festival ontem e hoje. Disponível em:

<http://www.festivaldeinverno.ufop.br/2008/home.php?idp=ofestival >.

Acesso em: 03/05/2009a.

Universidade Federal de Ouro Preto. Balanço do Festival de Inverno de Ouro Preto e Mariana - Fórum das Artes 2009. Relatório Geral da Pró-reitoria de Extensão. [S. 1: s. n.] [2009b].

UNESCO. Lista do Patrimônio Mundial no Brasil. Disponível em: <http://www.unesco.org/new/pt/brasilia/culture/world-heritage/list-of-world-heritagein-brazil/\#c154844>. Acesso em: 18/12/2010.

Recebido em: 01-09-2011.

Aprovado em: 01-10-2011. 